\title{
Results of treatment of trapeziometacarpal osteoarthritis with trapeziectomy and tendon allograft interposition
}

\author{
Nadine Hollevoet, Camille Thys, Lieselot Verens, Szabolcs Benis, Wim Vanhove \\ From the department of orthopaedic surgery, Ghent University Hospital, Ghent, Belgium.
}

The aim of the study was to evaluate the results of treatment of osteoarthritis of the carpometacarpal joint of the thumb with tendon allograft interposition. Fifty-three patients (61 hands), 13 men and 40 women, were operated on at a mean age of 61 years. A partial trapeziectomy with tendon interposition was performed in 19 hands and with suspension arthroplasty in 24 . Seventeen thumbs underwent a total trapeziectomy with suspension arthroplasty. Patients were evaluated at a mean follow-up of 4 years. In 34 patients (41 hands), a mean disability of arm, shoulder and hand score of 19 was found and a mean visual analogue scale for pain of 1.3 . The satisfaction rate was $83 \%$. Revision operations were performed in 8 out of 61 hands. Four of those thumbs had been operated on previously or did not have primary osteoarthritis. No revisions were needed after partial trapeziectomy and tendon allograft interposition with suspension arthroplasty. In conclusion, tendon allograft interposition can be considered as one of the treatment options for osteoarthritis of the carpometacarpal joint of the thumb.

Keywords: osteoarthritis trapeziometacarpal joint; carpometacarpal joint thumb; tendon allograft.

\section{INTRODUCTION}

A large number of operative techniques exist to treat osteoarthritis of the trapeziometacarpal joint indicating no single method works well for all

No benefits or funds were received in support of this study. None of the authors have a conflict of interest. patients. A few of the surgical options include total or partial trapeziectomy with autologous tendon graft interposition with or without suspension arthroplasty $(1,2)$. The flexor carpi radialis tendon is most frequently used, but this type of surgery can also be performed with the tendons of the palmaris longus (3), the abductor pollicis longus $(4,5)$, the extensor carpi radialis longus (6) and a strip of fascia lata (7).

With tendon allografts, operation time can be shortened and donor site morbidity avoided. Results of surgery with processed fascia lata allografts have been reported previously $(8,9,10,11)$. In the present study, fresh frozen human cadaveric tendons from the lower limb were used. One of the advantages of these tendon allografts is that large tendons with sufficient length and width are available and no foreign body reactions have been reported such as synovitis or osteolysis. Total joint prostheses and

Nadine Hollevoet: Orthopaedic Surgeon,

Camille Thys, medical student,

Lieselot Vekens, medical student,

- Szabolcs Benis, Orthopaedic surgeon,

- Wim Vanhove, Orthopaedic surgeon.

Department of orthopaedic surgery, Ghent University Hospital, Ghent, Belgium.

Correspondence : Nadine Hollevoet, Department of orthopaedic surgery, Ghent University Hospital, Ghent, Belgium. Phone: 003293322251.

Email : Nadine.hollevoet@ugent.be

- 2021, Acta Orthopædica Belgica. 
other implants made out of polyethylene, metal, ceramic, silicone or pyrocarbon may be susceptible to wear, may dislocate or show loosening $(12,13)$. Therefore, better results and/or lower revision rates with tendon allografts than with tendon autografts or prosthetic implants could be expected.

The aim of the present study was to determine outcomes and revision rates of the treatment of osteoarthritis of the trapeziometacarpal joint with trapeziectomy and tendon allograft interposition.

\section{PATIENTS AND METHODS}

A retrospective cohort study was performed. In the electronic medical files of the department of orthopaedic surgery was searched for all patients who were operated on for osteoarthritis of the trapeziometacarpal joint with tendon allograft interposition between 2006 and 2015. Primary or revision procedures with total or partial trapeziectomy, with or without suspension arthroplasty were included. Minimal follow-up had to be one year.

Patients who were operated on between 2005 and 2010 underwent a partial trapeziectomy and simple tendon allograft interposition or a total trapeziectomy with suspension arthroplasty, especially if there was associated osteoarthritis of the scaphotrapeziotrapezoidal (STT) joint. After 2010, tendon interposition alone was abandoned and a suspension arthroplasty was performed after partial trapeziectomy. It was expected that this would improve the stability of the base of the first metacarpal. Later, a partial trapeziectomy with suspension arthroplasty was also done in patients with asymptomatic osteoarthritis of the STT joint, because there was a concern that a total trapeziectomy could destabilise the carpus.

Surgical procedures were performed by the first author. Patients were operated on under general anaesthesia and upper arm tourniquet. The trapeziometacarpal joint was approached from dorsally and a total or partial resection of the distal articular part of the trapezium was performed. A fresh frozen tendon allograft of a muscle of the lower limb was used for interposition and/or suspension arthroplasty (ligament reconstruction).
In most cases, it was a tendon of the tibialis posterior muscle. If the tendon was too wide, it was longitudinally split and only a part of the tendon was used. In case of tendon allograft interposition without suspension arthroplasty, the tendon graft was sutured together in the shape of an anchovy with a 2/0 non-resorbable braided polyester suture. The dorsal capsule was closed to keep the tendon allograft in place. The suspension arthroplasty was done according to the method described by Weilby (14), except that the tendon allograft was wound only once around the tendons of the abductor pollicis longus and flexor carpi radialis before being sutured to itself. The space between the base of the first metacarpal and scaphoid was filled up with the remaining ends of the tendon allograft tied and sutured together with PDS, non-resorbable braided polyester or nylon $2 / 0$. The joint capsule was closed with PDS or Vicryl 4/0 and the skin with separate $5 / 0$ nylon stitches. Postoperatively, a forearm cast was applied including the thumb. After one week the skin sutures were removed and a synthetic cast was applied allowing the wrist, the long fingers and the interphalangeal joint of the thumb free to move. One month postoperatively, patients were encouraged to move the thumb by themselves. In case of pain, a removable splint was intermittently worn a few more months until the pain had subsided. A tendon allograft rolled as an anchovy ready for

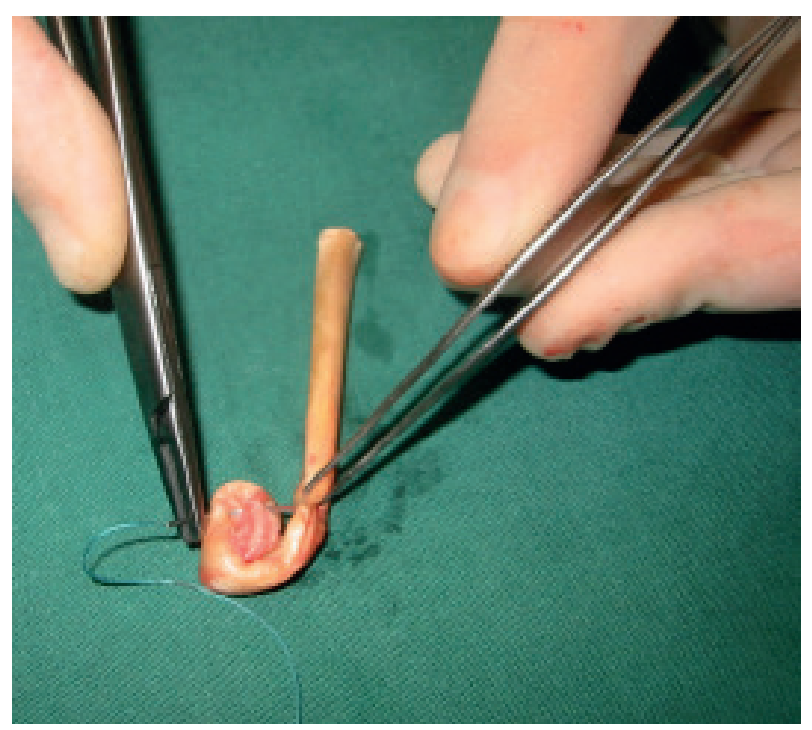

Figure 1. - Tendon allograft rolled up as an achovy. 


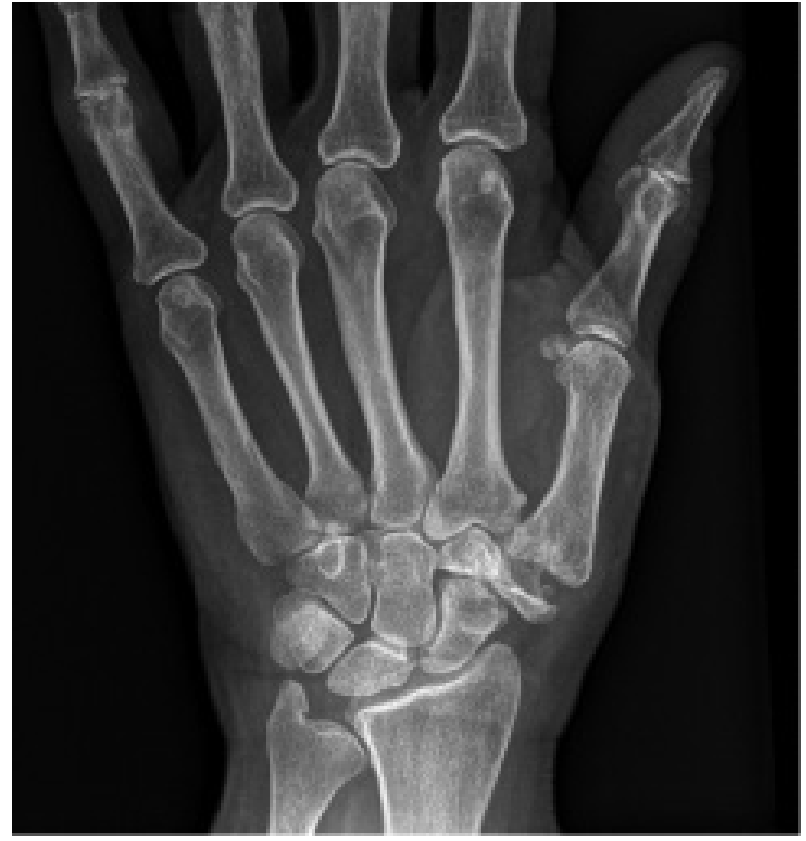

Figure 2. - Radiograph taken 6 years after partial trapeziectomy and tendon allograft interposition in a women operated on at the age of 58 years.
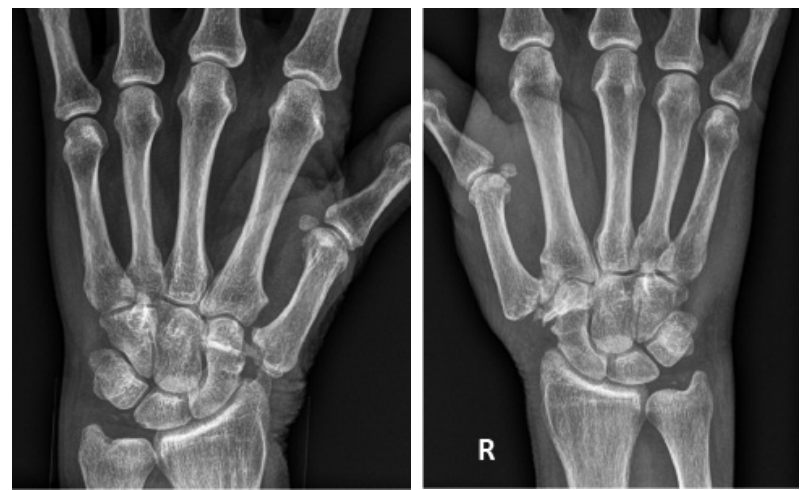

Figure 3. - Bilateral radiographs of a 64-year-old women taken in 2016 after total trapeziectomy and suspension arthroplasty in the left wrist in 2012 and a partial trapeziectomy and suspension arthroplasty in the right wrist in 2013.

interposition is shown in Figure 1. Radiographs of a hand after partial trapeziectomy and tendon allograft interposition without suspension arthroplasty are shown in Figure 2 and of total and partial trapeziectomy with suspension arthroplasty in Figure 3.

In the medical files was looked for information about sex and age of the patients at the time they were operated on, indication, operated side, type of surgical procedure, which tendon allograft was used and it was noted if patients had been operated on previously for trapeziometacarpal osteoarthritis. The staging of the osteoarthritis of the trapeziometacarpal joint was done according to Eaton (1) on preoperative digital X-rays of patients with primary osteoarthritis. In the total group of patients was recorded if additional operations had been performed after the tendon allograft interposition and at what time.

Patients were invited to visit the hospital to fill in questionnaires and to undergo clinical examination. If they were not able to come, they were interviewed by telephone.

Patients were asked to fill in the Dutch version of the disability of arm, shoulder and hand (DASH) score to have an idea about the function of their hand (15). A visual analogue scale (VAS) for pain ranged from 0 to 10 . Zero meant no pain and 10 the worst imaginable pain. The level of satisfaction ranged from 1 to 5 . A score of 1 meant: very satisfied, 2: satisfied, 3: neutral, 4: not satisfied and 5: very dissatisfied. If both hands had been operated on, patients filled in two scores, one for the left and one for the right hand.

Measurement of the key pinch was done with a calibrated pinch gauge (Jamar). The Kapandji score was determined to have an idea about the flexion and adduction mobility of the thumb (16). Thumb abduction was measured with a goniometer as the maximal angle between the axis of the thumb and index metacarpal. Patients were evaluated by two investigators (CT and LV) who were not involved in the treatment.

No statistical analysis was performed to test the difference in outcome between the 3 types of surgical procedures because the numbers of the subgroups was too small.

Approval from the ethical committee of the hospital was obtained (registration number: B670201629021).

\section{RESULTS}

Fifty-three patients (61 hands) were operated on between 2006 and 2015. Thirteen patients were male 
Table I. — Subjective outcomes

\begin{tabular}{|l|c|c|c|c|}
\hline & $\begin{array}{c}\text { All procedures } \\
\mathrm{N}=41\end{array}$ & $\begin{array}{c}\text { Total trapeziectomy }+ \\
\text { suspension arthroplasty } \\
\mathrm{N}=9\end{array}$ & $\begin{array}{c}\text { Partial trapeziectomy } \\
+ \text { tendon interposition } \\
\mathrm{N}=12\end{array}$ & $\begin{array}{c}\text { Partial trapeziectomy }+ \\
\text { suspension arthroplasty } \\
\mathrm{N}=20\end{array}$ \\
\hline Mean follow-up in years (range) & $4.5(1,10)$ & $3.8(1,5)$ & $8(1.5,10)$ & $2.7(1,5.5)$ \\
\hline Mean DASH score (range) & $19(0,84)$ & $22(1,49)$ & $21(0,84)$ & $17(0,59)$ \\
\hline Mean VAS score for pain (range) & $1.3(0,7)$ & $1.6(0,7)$ & $0.8(0,4)$ & $1.5(0,5)$ \\
\hline Percentage satisfied + very satisfied & 83 & 75 & 78 & 89 \\
\hline
\end{tabular}

Table II. - Results of clinical examination

\begin{tabular}{|l|c|c|c|c|}
\hline & $\begin{array}{c}\text { All procedures } \\
\mathrm{N}=29\end{array}$ & $\begin{array}{c}\text { Total trapeziectomy }+ \\
\text { suspension arthroplasty } \\
\mathrm{N}=7\end{array}$ & $\begin{array}{c}\text { Partial trapeziectomy }+ \\
\text { tendon interposition } \\
\mathrm{N}=6\end{array}$ & $\begin{array}{c}\text { Partial trapeziectomy }+ \\
\text { suspension arthroplasty } \\
\mathrm{N}=16\end{array}$ \\
\hline Mean follow-up in years (range) & $4.4(1,10)$ & $4(3,5)$ & $9(8,10)$ & $2.7(1,4.5)$ \\
\hline Mean Key pinch (range) & $5.5 \mathrm{~kg}(2,17)$ & $7 \mathrm{~kg}(2,10)$ & $7 \mathrm{~kg}(4,19)$ & $5 \mathrm{~kg}(2,8)$ \\
\hline Mean thumb abduction (range) & $56^{\circ}(0,88)$ & $47^{\circ}(0,88)$ & $57^{\circ}(35,80)$ & $60^{\circ}(53,67)$ \\
\hline Mean Kapandji score (range) & $9.3(5,10)$ & $8(5,10)$ & $10(10)$ & $9.5(7,10)$ \\
\hline
\end{tabular}

Table III. - Revision operations

\begin{tabular}{|c|c|c|c|c|c|}
\hline $\begin{array}{l}\text { Sex, age in } \\
\text { years }\end{array}$ & indication & $\begin{array}{l}\text { Type of allograft } \\
\text { procedure }\end{array}$ & Reason revision & Reoperation & $\begin{array}{l}\text { Time after } \\
\text { allograft } \\
\text { procedure }\end{array}$ \\
\hline Man, 63 & $\begin{array}{c}\text { Primary } \\
\text { osteoarthritis }\end{array}$ & $\begin{array}{c}\text { Total trapeziectomy }+ \\
\text { suspension arthroplasty }\end{array}$ & Infection & $\begin{array}{l}\text { Removal of tendon } \\
\text { allograft }\end{array}$ & 3 weeks \\
\hline Man, 40 & $\begin{array}{c}\text { Osteoarthritis }+ \\
\text { spasticity }\end{array}$ & $\begin{array}{c}\text { Total trapeziectomy }+ \\
\text { suspension arthroplasty }\end{array}$ & $\begin{array}{l}\text { Adduction contracture } \\
\text { first web }\end{array}$ & Intermetacarpal arthrodesis & 3 months \\
\hline Man, 65 & Primary osteoartritis & $\begin{array}{c}\text { Partial trapeziectomy }+ \\
\text { tendon interposition }\end{array}$ & Persistent pain & $\begin{array}{c}\text { Total trapeziectomy }+ \\
\text { suspension arthroplasty }\end{array}$ & 7 months \\
\hline Man, 61 & $\begin{array}{l}\text { Posttraumatic } \\
\text { osteoarthritis }\end{array}$ & $\begin{array}{c}\text { Total trapeziectomy }+ \\
\text { suspension arthroplasty }\end{array}$ & $\begin{array}{l}\text { Persistent pain ST } \\
\text { joint, MCP joint } \\
\text { hyperextension }\end{array}$ & $\begin{array}{l}\text { ST joint interposition with } \\
\text { donor cartilage graft and } \\
\text { MCP joint arthrodesis }\end{array}$ & 13 months \\
\hline Woman, 53 & $\begin{array}{l}\text { Pseudarthrosis } \\
\text { trapeziometacarpal } \\
\text { joint arthrodesis }\end{array}$ & $\begin{array}{l}\text { Partial trapeziectomy }+ \\
\text { tendon interposition }\end{array}$ & Persistent pain & $\begin{array}{l}\text { Total trapeziectomy plus } \\
\text { tendon interposition }\end{array}$ & 10 months \\
\hline Man, 55 & $\begin{array}{c}\text { Primary } \\
\text { osteoarthritis }\end{array}$ & $\begin{array}{l}\text { Partial trapeziectomy }+ \\
\text { tendon interposition }\end{array}$ & Persistent pain & $\begin{array}{l}\text { Additional bone resection } \\
\text { from the trapezium }\end{array}$ & 6 months \\
\hline Woman, 66 & $\begin{array}{c}\text { Primary } \\
\text { osteoarthritis }\end{array}$ & $\begin{array}{c}\text { Partial trapeziectomy }+ \\
\text { tendon interposition }\end{array}$ & Persistent pain & $\begin{array}{l}\text { Additional bone resection } \\
\text { from the trapezium }\end{array}$ & 6 months \\
\hline Woman, 54 & $\begin{array}{c}\text { Failed total } \\
\text { trapeziectomy } \\
+ \text { suspension } \\
\text { arthroplasty with } \\
\text { flexor carpi radialis }\end{array}$ & Suspension arthroplasty & $\begin{array}{l}\text { Persistent pain ST } \\
\text { joint, abutment } \\
\text { between base first } \\
\text { metacarpal and } \\
\text { scaphoid }\end{array}$ & Pyrocarbon implant & 2 months \\
\hline
\end{tabular}

ST: scaphotrapezoid, MCP: metacarpophalangeal.

and 40 female. Mean age at the time of surgery was 61 years (range: 39-85). Twenty-nine procedures were done on the right hand and 32 on the left. Forty-eight procedures were performed for primary osteoarthritis of the trapeziometacarpal joint and in 13 thumbs operations were done for secondary causes of osteoarthritis or after previous failed surgery for osteoarthritis of the trapeziometacarpal joint. A partial trapeziectomy with tendon interposition alone was done in 19 hands and with 
suspension arthroplasty in 24 . In 17 cases a total trapeziectomy with suspension arthroplasty was performed. There was only one case with a total trapeziectomy and tendon interposition without suspension arthroplasty.

Nineteen patients (20 hands), 3 men and 16 women, were lost for functional and clinical followup. One patient had died, the others could not be contacted or declined to participate. Mean age at the time of surgery of patients who were lost to followup was 65 years (range:44-85).

Thirty-four patients (41 hands) in 10 men and 24 women were evaluated by questionnaire and/ or clinical examination. Twenty-three patients (29 hands) came to the hospital and 11 patients (12 hands) were interviewed by telephone. Mean age of the 34 patients at the time of surgery was 59 years (range: 39-72). In 32 hands surgery was done for primary osteoarthritis, in four after failure of a total joint prosthesis, in one after an extension osteotomy of the first metacarpal, in one there was spasticity caused by a brain injury and in two posttraumatic osteoarthritis. Of the 32 hands with primary osteoarthritis the Eaton classification was stage two in 12, stage three in 9 and stage four in 3 hands. Preoperative X-rays were missing in 8 hands. A partial trapeziectomy without tendon interposition was done in 12 hands and with an associated ligament reconstruction in 20. In 9 cases a total trapeziectomy with tendon interposition and ligament reconstruction was performed. In 22 hands a tibialis posterior tendon allograft was used, in 8 fascia lata, in 4 a gracilis and in 4 a semitendinosis tendon. In 4 cases the type of tendon was not mentioned in the file.

Results of the operated hands of all patients who participated and of the subgroups are shown in tables I and II. Twenty patients ( $57 \%$ ) were very satisfied, $9(26 \%)$ satisfied, 1 (3\%) neutral, 4 $(11 \%)$ dissatisfied and of 1 (3\%) very dissatisfied. Five patients (6 hands) had not replied if they were satisfied.

In $8(13 \%)$ of the 61 operated hands, a revision operation was needed after the tendon allograft interposition (Table III). In patients operated on for primary osteoarthritis, without previous surgery of the trapeziometacarpal joint, a surgical reintervention was required in 4 hands $(6.5 \%)$. No revisions were required so far in patients who underwent partial trapeziectomy with a suspension arthroplasty.

\section{DISCUSSION}

To our knowledge this is the first study reporting results of the treatment of osteoarthritis of carpometacarpal joint of the thumb with fresh frozen tendon allografts of the lower limb. Previously, outcomes of processed fascia lata allografts have been published. van der Veen et al. (8) reported results of 36 patients ( 38 hands) who underwent a fascia lata interposition after total trapeziectomy without suspension arthroplasty or ligament reconstruction. Mean DASH score was 25 and only 64 $\%$ of patients were satisfied. In 5 hands the fascia lata allograft was removed surgically and in 2 spontaneously because of infection or dislocation. Taghinia et al. reported good outcomes with fascia lata interposition and suspension arthroplasty with a bone anchor in 46 hands (17 underwent partial and 29 total trapeziectomy). No reoperations were required (9). In the study of Givissis et al., a total trapeziectomy and allograft interposition without ligament reconstruction but with K-wire fixation of the first metacarpal for 5 weeks was performed in 31 thumbs in 24 patients. No revisions had been needed at a follow up of between 10 and 15 years (10). Spaans et al. reported results of fascia lata allograft interposition in 22 patients with partial trapeziectomy without suspension arthroplasty. Mean DASH score was 37. Two patients (9\%) had reoperations in the first year after the initial operation because of ongoing pain (11).

Besides tendon allografts, a dermal allograft is another biological treatment option. Results of a suspension-interposition arthroplasty with the use of a dermal allograft were compared with the tendon of the flexor carpi radialis. Thirtyone patients received a dermal allograft and 29 a flexor carpi radialis tendon. One allograft had to be removed because of persistent pain and allografts caused more tendon complications (partial rupture and tendonitis of the flexor carpi radialis) and were therefore not recommended as a first choice procedure (17). 
Forty-three trapeziometacarpal arthroplasties with a bovine tendon collagen graft and 415 with autologous tendons were evaluated in a study of Wilkens et al. The rate of unplanned reoperations was higher with bovine than with autologous tendons ( $9 \%$ versus $4 \%)$. In the group of autologous tendons were two unplanned reoperations for infection and one for an extruded tendon graft that caused protuberance, and the rest were for persistent pain. Mean time of reoperation averaged 24 months after the first procedure (18).

Mean DASH score in the present study was 19 , mean key pinch $5.5 \mathrm{~kg}$ and satisfaction rate $83 \%$. These outcomes are comparable with other treatment options for osteoarthritis of the carpometacarpal joint of the thumb such as total or partial trapeziectomy with autologous tendon interposition with or without suspension arthroplasty (19). With total joint arthroplasty, Andrezejewski and Ledoux, reported in a study with a similar follow-up as in the present study, a mean DASH score of 27, a mean key pinch of $4.8 \mathrm{~kg}$ and a satisfaction rate of $92 \%$ in 113 hands (20).

In the present study, revisions were performed in 8 hands $(13 \%)$. If only patients with primary osteoarthritis were considered, then 4 reoperations $(6.5 \%)$ were needed, in 3 of those it was after a partial trapeziectomy and tendon interposition without suspension arthroplasty or ligament reconstruction. In the studies with processed fascia lata allograft interposition, higher revision rates or failures were found if only an interposition was done without suspension or fixation $(18 \%$ in the study of van der Veen et al. (7) and 9\% in the study of Spaans et al. (11)). No revisions were required after stabilization with bone anchors or K-wires $(9,10)$.

High revision rates with some type of total joint prostheses and synthetic implants have been reported (12,13). Robles Molina et al., compared retrospectively reoperation rates of the Arpe prosthesis with trapeziectomy and flexor carpi radialis tendon interposition and ligament reconstruction. The reoperation rate was $10 \%$ for the prosthesis and $6 \%$ for the tendon procedure at a mean follow-up of 4.8 years (21). A revision rate of $12.4 \%$ was found in the study of Adrezejewski and Ledoux with the Maia prosthesis (20).
Low long-term revision rates of approximately $3 \%$ have been reported after simple trapeziectomy and trapeziectomy with ligament reconstruction and tendon interposition or suspensionplasty (3). In a systematic review, the lowest failure rate for nonimplant techniques was found for trapeziectomy with ligament reconstruction and tendon interposition. The overall failure rate was 0.24 per 100 procedure-years. It had not been investigated if there was a difference in partial or total trapeziectomy. Higher failure rates were reported for simple trapeziectomy, arthrodesis and surgery with implants (22).

In the present study, revision rates with tendon allografts were higher than with autologous tendons, but the risk that patients may need a reoperation after 10 years is likely to be less than with total joint arthroplasty. Revision surgery after tendon allograft procedures was performed within the first year after the operation. With total joint prostheses, more revisions can be expected with the passing of the years. We deplored 1 infection, but no problems with foreign body reactions, although no X-rays or histological examination were done to find or exclude this.

Limitations of the present study are that is a retrospective study and no information was available about the preoperative DASH score, pain, key pinch, thumb abduction and Kapandji score. No $\mathrm{X}$-rays were taken at the time of follow-up. Only information about major complications requiring a surgical reintervention was reported. The group of patients was heterogeneous. Not all patients had primary osteoarthritis and revision cases were also included. Three different types of surgery were performed and it could not be determined which technique was the best because of the small number of patients.

It can be concluded that results of tendon allograft interposition after total or partial trapeziectomy with or without suspension arthroplasty may be comparable to other procedures to treat osteoarthritis of the carpometacarpal joint of the thumb. It is one of the many treatment options that can be offered to patients who need primary or revision surgery for trapeziometacarpal osteoarthritis. However, revision rates with tendon allografts in the present 
study were higher than with autologous tendon interposition reported in other studies. It seems that the risk of reoperation is higher if only tendon interposition without suspension or ligament reconstruction is performed.

\section{REFERENCES}

1. Eaton RG, Glickel SZ, Littler JW. Tendon interposition arthroplasty for degenerative arthritis of the trapeziometacarpal joint of the thumb. J Hand Surg Am. 1985 Sep; 10(5): 645-654.

2. Vermeulen GM, Slijper H, Feitz R, Hovius SER, Mooijen TM, Selles RW. Surgical management of primary thumb carpometacarpal osteoarthritis: A systematic review. J Hand Surg Am. 2011 Jan; 36(1): 157-169.

3. Gangopadhyay S, McKenna H, Burke FD, Davis TRC. Five- to 18-year follow-up for treatment of trapeziometacarpal osteoarthritis: a prospective com-parison of excision, tendon interposition, and ligament reconstruction and tendon interposition. J Hand Surg Am. 2012 Mar; 37(3): 411-7.

4. Robinson D, Aghasi M, Halperin N. Abductor pollicis longus tendon arthroplasty of the trapezio-metacarpal joint: surgical technique and results. J Hand Surg Am. 1991 May; 16(3): 504-9.

5. Sigfusson R, Lundborg G. Abductor pollicis longus tendon arthroplasty for treatment of arthrosis in the first carpometacarpal joint. Scand J Plast Reconstr Hand Surg. 1991; 25(1): 73-7.

6. Necking LE, Eiken O. ECRL-strip plasty for metacarpal base fixation after excision of the trapezium. Scand J Plast Reconstr Surg. 1986; 20(2): 229-33.

7. Wilson JN. Arthroplasty of the trapezio-metacarpal joint. Plast Reconstr Surg. 1972 Feb; 49(2): 143-8.

8. van der Veen FJC, Strackee SD, Karim RB, Hage JJ. Poor results after interpositional arthroplasty with fascia lata allograft for arthritis of the trapezio-metacarpal joint. Eur J Plast Surg. 2007 Jan;2 9: 257-262.

9. Taghinia AH, Al-Sheikh AA, Upton J. Suture anchor suspension and fascia lata interposition arthroplasty for basal joint arthritis of the thumb. Plast Reconstr Surg. 2008 Aug; 122(2): 497-504.

10. Givissis P, Sachinis NP, Akritopoulos P, Stavridis SI, Christodoulou A. The "pillow" technique for thumb carpometacarpal joint arthritis: cohort study with 10- to 15year follow-up. J Hand Surg Am. 2016 Jul; 41(7): 775-81.
11. Spaans AJ, Weijns ME, Braakenburg A, van Minnen LP van der Molen AB. Partial trapeziectomy and interposition of fascia lata allograft in the operative treatment of thumb base osteoarthritis. J Plast Surg Hand Surg. 2016; 50(1): 35-9.

12. Huang K, Hollevoet N, Giddins G. Thumb carpometacarpal joint total arthroplasty: a systematic review. J Hand Surg Eur Vol. 2015 May; 40(4): 38-50.

13. Vitale MA, Taylor F, Ross M, Moran SL. Trapezium prosthetic arthroplasty (silicone, artelon, metal and pyrocarbon). Hand Clin. 2013 Feb; 29(1): 37-55.

14. Weilby A. Tendon interposition arthroplasty of the first carpo-metacarpal joint. J Hand Surg Br. 1988 Nov; 13(4): 421-5.

15. Veehof MM, Sleegers EJ, van Veldhoven NH, Schuurman AH, van Meeteren NL. Psychometric qualities of the Dutch language version of the disabilities of the arm, shoulder, and hand questionnaire (DASH-DLV). $J$ Hand Ther. 2002 Oct-Dec; 15(4): 347-54.

16. Kapandji A. Clinical test of apposition and counterapposition of the thumb. Ann Chir Main. 1986; 5(1): 67-73.

17. Marks M, Hensler S, Wehrli M, Scheibler AG, Schindele S, Herren DB. Trapeziectomy with suspensioninterposition arthroplasty for thumb carpometacarpal osteoarthritis: A randomized controlled trial comparing the use of allograft versus flexor carpi radialis tendon. J Hand Surg Am. 2017 Dec; 42(12): 978-986.

18. Wilkens SC, Xue Z, Mellema JJ, Ring D, Chen N. Unplanned reoperation after trapeziometacarpal arthroplasty: rate, reasons and risk factors. Hand (NY). 2017 Sept; 12(5): 446-452.

19. Ceruso M, Munz G, Carulli C. et al. Thumb TMC osteoarthritis. Evidence based data in hand surgery and therapy. In: Instructional course book FESSH 2017 Budapest, Grey Giddins and Gürsel Leblebicioglu, editors, Iris publications. P: 369-403

20. Andrzejewski A, Ledoux P. Maïa ${ }^{\circledR}$ trapeziometacarpal joint arthroplasty: Survival and clinical outcomes at 5 years' follow-up. Hand Surg Rehabil. 2019 Jun; 38(3): 169-173.

21. Robles-Molina MJ, López-Caba F, Gómez-Sánchez RC, Cárdenas-Grande E, Pajares-López M, HernándezCortés $\mathbf{P}$. Trapeziectomy with ligament reconstruction and tendon interposition versus a trapeziometacarpal prosthesis for the treatment of thumb basal joint osteoarthritis. Orthopedics. 2017 Jul 1; 40(4): e681-e686.

22. Ganhewa AD, Wu R, Chae MP. et al. Failure rates of base of thumb arthritis surgery: A systematic review. J Hand Surg Am. 2019 Sep; 44(9): 728-741. 